\title{
Relationship of Smartphone Dependence to General Health Status and Personality Traits among University Students
}

\author{
Masahiro Toda1,2*, Satoko Ezoe ${ }^{3}$, Kanae Mure ${ }^{2}$, Tatsuya Takeshita ${ }^{2}$ \\ ${ }^{1}$ Graduate School of Human Life Sciences, Notre Dame Seishin University, Okayama, Japan \\ ${ }^{2}$ Department of Public Health, Wakayama Medical University, Wakayama, Japan \\ ${ }^{3}$ Shimane University Health Service Center Izumo, Shimane, Japan \\ Email: ${ }^{\star} \mathrm{mt} @$ post.ndsu.ac.jp
}

How to cite this paper: Toda, M., Ezoe, S., Mure, K. and Takeshita, T. (2016) Relationship of Smartphone Dependence to General Health Status and Personality Traits among University Students. Open Journal of Preventive Medicine, 6, 215-221.

http://dx.doi.org/10.4236/ojpm.2016.610020

Received: August 31, 2016

Accepted: October 8, 2016

Published: October 11, 2016

Copyright (๑) 2016 by authors and Scientific Research Publishing Inc. This work is licensed under the Creative Commons Attribution International License (CC BY 4.0).

http://creativecommons.org/licenses/by/4.0/ (c) (i) Open Access

\begin{abstract}
We investigated associations between smartphone dependence and general health status or personality traits. To 197 medical university students, we administered a set of self-reporting questionnaires designed to evaluate these parameters. For males, smartphone dependence positively correlated with somatic symptoms, anxiety and insomnia, and emotional instability, and negatively correlated with agreeableness. For females, smartphone dependence positively correlated with somatic symptoms, severe depression, and extraversion, and negatively correlated with social dysfunction. These findings suggest that smartphone dependence may be associated with general health status or personality traits and that there may be a gender difference in these associations.
\end{abstract}

\section{Keywords}

Dependence, General Health Status, Personality Traits, Smartphone, University Students, Wakayama Smartphone-Dependence Scale (WSDS)

\section{Introduction}

Smartphones, which first became widely available in Japan in 2008, have rapidly come into widespread use. At the end of 2014, household penetration in Japan was 64.2\%, and use was particularly common (94.5\%) among people in their twenties [1]. Smartphones are more like tablet computers than mobile phones, and therefore may herald another change in the way mobile telecommunications are used. For example, $54.0 \%$ of smartphone subscribers answered that their frequency of use of Internet services in- 
creased after acquisition of a smartphone [1]. On smartphones, new communication tools such as social networking service (SNS) are more easily accessible. Thus, compared to simpler mobile phone handsets, while bringing greater convenience, smartphones also carry the potential for abuse, including use that leads to risky inattention in public places and excessive use or even dependence.

Viewing problematic smartphone use as a type of technostress [2], we recently developed a new scale for gauging smartphone dependence, the Wakayama SmartphoneDependence Scale (WSDS), and confirmed its reliability and validity [3]. In a recent study in which it was applied we found that smartphone dependence can be predicted by factors such as gender, mode of residence, chronotype, and depressive state [4]. At the same time, however, we concluded that other factors might also contribute to smartphone dependence.

In the present study, by analyzing the responses of medical university students, we examined associations between smartphone dependence and general health status or personality traits. Studies have been emerging, such as a report associating smartphone overuse with depression and anxiety [5], but there are still very few comprehensive examinations of the health implications of smartphone dependence. Meanwhile, previous studies have suggested that dependence on some of the functions provided by mobile phone is associated with personality traits [6] [7].

\section{Materials and Methods}

\subsection{Subjects}

For the study, approved by the Ethics Committee of the Wakayama Medical University, we enrolled 197 medical university students. After informed consent was obtained, the participants filled out a set of self-reporting questionnaires designed to evaluate smartphone use, general health status, and personality traits. Of 190 respondents who possessed smartphones, 184 respondents properly completed all the questionnaire items. Statistical analysis was performed for 140 respondents (87 males, 53 females) who reported using smartphones mainly to access the Internet. Mean $( \pm S D)$ age for males was $21.2 \pm 2.1$ years and for females $20.8 \pm 1.6$ years. In our previous study, we found that respondents using smartphones mainly to access the Internet had statistically significantly higher scores, both total and for each WSDS subscale, than respondents who used other devices mainly to access the Internet [3]. Incidentally, in this study, the former also reported greater daily use of smartphones (170.4 \pm 113.5 vs. $130.5 \pm 99.1 \mathrm{~min}$, $t=2.07, p<0.05)$.

\subsection{Smartphone Dependence}

Smartphone dependence was evaluated using the WSDS [3], a 21-item self-rating scale with 3 subscales (each comprising 7 items): Subscale 1, immersion in Internet communication; Subscale 2, using a smartphone for extended periods of time and neglecting social obligations and other tasks; Subscale 3, using a smartphone while doing something else and neglect of etiquette. Each response is scored on a Likert scale $(0,1,2,3)$. 
Likert scores for each item are then summed to provide subscales (ranging from 0 to 21) and overall (ranging from 0 to 63) scores of smartphone dependence. Higher scores indicate greater dependence.

\subsection{General Health Status}

General health status was assessed using the 28-item General Health Questionnaire (GHQ-28) [8], a self-rating questionnaire which consists of four 7-item scales measuring somatic symptoms, anxiety and insomnia, social dysfunction, and severe depression. The scores for each subscale range from 0 to 7 . In each section, higher scores indicate poorer health status.

\subsection{Personality Traits}

Personality traits were assessed using the 10-item Personality Inventory (TIPI) [9], a self-rating questionnaire which consists of 2 items for each of the "Big Five" personality dimensions: extraversion; agreeableness; conscientiousness; emotional instability; openness to experience. The scores for each trait range from 2 to 14 . Higher scores indicate a greater degree of that trait.

\subsection{Statistical Analysis}

Before statistical analysis, Kolmogorov-Smirnov testing of normal distribution was conducted. Since none of the GHQ-28 subscale scores passed this test, we used Spearman's correlation coefficients to analyze the relationships of these scores to the WSDS subscale scores. Relationships between WSDS subscale and TIPI subscale scores were analyzed using Pearson's correlation coefficients. Values were considered to be statistically significantly different when $p<0.05$.

\section{Results}

Table 1 shows scores for smartphone dependence. No statistically significant differences were found between males and females in WSDS total and WSDS subscale scores.

Table 2 shows relationships between smartphone dependence and general health

Table 1. Scores for smartphone dependence.

\begin{tabular}{cccc}
\hline & Males $(\mathrm{n}=87)$ & Females $(\mathrm{n}=53)$ & $p^{*}$ \\
\hline $\begin{array}{c}\text { Wakayama Smartphone-Dependence Scale } \\
\text { (WSDS) }\end{array}$ & & & \\
Subscale 1 & $5.2 \pm 3.1$ & $4.9 \pm 2.9$ & 0.52 \\
Subscale 2 & $9.7 \pm 3.8$ & $11.0 \pm 4.0$ & 0.07 \\
Subscale 3 & $13.2 \pm 3.8$ & $13.8 \pm 3.7$ & 0.36 \\
Total & $28.2 \pm 8.6$ & $29.7 \pm 8.4$ & 0.32 \\
\hline
\end{tabular}

Values are expressed as mean \pm SD. ${ }^{*}$ Student's $t$ test. Subscale 1, immersion in Internet communication; Subscale 2, using a smartphone for extended periods of time and neglecting social obligations and other tasks; Subscale 3, using a smartphone while doing something else and neglect of etiquette. 
status. For males, we detected statistically significant correlations between WSDS subscale 2 scores and somatic symptoms ( $\rho=0.31, p<0.01)$ and anxiety and insomnia ( $\rho=$ $0.36, p<0.01$ ). Correlations between subscales 1 and 3 and GHQ-28 subscale scores were not apparent. Meanwhile, for females, we detected statistically significant correlations between scores for subscale 2 and somatic symptoms $(\rho=0.39, p<0.01)$ and severe depression $(\rho=0.29, p<0.05)$. In addition, we found a statistically significant negative correlation between subscale 3 scores and social dysfunction $(\rho=-0.41, p<$ $0.01)$. Female subscale 1 scores showed no correlation with any of the GHQ-28 subscales.

Table 3 shows relationships between smartphone dependence and personality traits. For males, scores of WSDS subscales $1(r=-0.26, p<0.05), 2(r=-0.41, p<0.01)$, and $3(r=-0.39, p<0.01)$ negatively correlate with agreeableness. The WSDS subscale 2 score also correlates with emotional instability $(r=0.24, p<0.05)$. Meanwhile, for females, a statistically significant correlation between WSDS subscale 3 score and extraversion is apparent $(r=0.37, p<0.01)$. Subscales 1 and 2 scores show no correlation with any personality traits.

\section{Discussion}

Both for males and females, WSDS subscale 2 is associated with somatic symptoms. Previous studies have reported that extended use of mobile phones or other electronic devices may be associated with pain in the neck and shoulders and low back pain [10] [11]. Such musculoskeletal symptoms may be due to maintaining posture for too long

Table 2. Spearman's correlation coefficients between scores for smartphone dependence and mental health status.

\begin{tabular}{|c|c|c|c|c|}
\hline & \multicolumn{4}{|c|}{ 28-item General Health Questionnaire } \\
\hline & $\begin{array}{c}\text { Somatic } \\
\text { symptoms }\end{array}$ & $\begin{array}{l}\text { Anxiety and } \\
\text { insomnia }\end{array}$ & $\begin{array}{c}\text { Social } \\
\text { dysfunction }\end{array}$ & $\begin{array}{c}\text { Severe } \\
\text { depression }\end{array}$ \\
\hline \multicolumn{5}{|l|}{ Males $(\mathrm{n}=87)$} \\
\hline \multirow{2}{*}{\multicolumn{5}{|c|}{$\begin{array}{c}\text { Wakayama } \\
\text { Smartphone-Dependence Scale }\end{array}$}} \\
\hline & & & & \\
\hline Subscale 1 & 0.09 & 0.08 & 0.15 & 0.04 \\
\hline Subscale 2 & $0.31^{* *}$ & $0.36^{* *}$ & 0.11 & 0.05 \\
\hline Subscale 3 & 0.14 & 0.06 & -0.06 & 0.04 \\
\hline \multicolumn{5}{|l|}{ Female $(n=53)$} \\
\hline \multirow{2}{*}{\multicolumn{5}{|c|}{$\begin{array}{c}\text { Wakayama } \\
\text { Smartphone-Dependence Scale }\end{array}$}} \\
\hline & & & & \\
\hline Subscale 1 & 0.05 & 0.07 & 0.03 & 0.14 \\
\hline Subscale 2 & $0.39^{* *}$ & 0.26 & -0.07 & $0.29^{*}$ \\
\hline Subscale 3 & -0.03 & 0.27 & $-0.41^{\star *}$ & 0.22 \\
\hline
\end{tabular}

${ }^{*} p<0.05,{ }^{* *} p<0.01$. Subscale 1, immersion in Internet communication; Subscale 2, using a smartphone for extended periods of time and neglecting social obligations and other tasks; Subscale 3, using a smartphone while doing something else and neglect of etiquette. 
Table 3. Pearson's correlation coefficients between scores for smartphone dependence and personality traits.

\begin{tabular}{|c|c|c|c|c|c|}
\hline & \multicolumn{5}{|c|}{ 10-item Personality Inventory } \\
\hline & Extraversion & Agreeableness & Conscientiousness & $\begin{array}{l}\text { Emotional } \\
\text { instability }\end{array}$ & $\begin{array}{l}\text { Openness to } \\
\text { experience }\end{array}$ \\
\hline \multicolumn{6}{|l|}{ Males $(\mathrm{n}=87)$} \\
\hline \multirow{2}{*}{\multicolumn{6}{|c|}{$\begin{array}{c}\text { Wakayama } \\
\text { Smartphone-Dependence Scale }\end{array}$}} \\
\hline & & & & & \\
\hline Subscale 1 & -0.06 & $-0.26^{*}$ & 0.07 & 0.01 & -0.06 \\
\hline Subscale 2 & 0.05 & $-0.41^{\star *}$ & -0.10 & $0.24^{\star}$ & -0.06 \\
\hline Subscale 3 & 0.18 & $-0.39^{* *}$ & 0.09 & 0.003 & 0.05 \\
\hline \multicolumn{6}{|l|}{ Female $(\mathrm{n}=53)$} \\
\hline \multicolumn{6}{|c|}{$\begin{array}{c}\text { Wakayama } \\
\text { Smartphone-Dependence Scale }\end{array}$} \\
\hline Subscale 1 & -0.11 & -0.16 & 0.10 & 0.18 & 0.10 \\
\hline Subscale 2 & 0.17 & 0.21 & -0.14 & 0.02 & 0.15 \\
\hline Subscale 3 & $0.37^{\star *}$ & -0.02 & -0.07 & 0.21 & 0.21 \\
\hline
\end{tabular}

${ }^{*} p<0.05,{ }^{* *} p<0.01$. Subscale 1, immersion in Internet communication; Subscale 2, using a smartphone for extended periods of time and neglecting social obligations and other tasks; Subscale 3, using a smartphone while doing something else and neglect of etiquette.

or to loading from thumb movements [12]. For males, subscale 2 is also associated with anxiety and insomnia. Previous studies have suggested that extended use of mobile phones at night might delay the sleep phase [13] [14]. This may be associated with display brightness [15]. For females, the same tendency was observed, but it did not reach statistical significance $(r=0.26, p=0.06)$. Plausibly, it could be suggested that males tend, more than females, to use smartphones at night. Previous studies also found that males, compared to females, access to the Internet longer before sleep and play video games more often in bedrooms [13] [15].

For females, we found a significant negative correlation between subscale 3 and social dysfunction: that is, "using a smartphone while doing something else and neglect of etiquette" was associated with activeness. Moreover, subscale 3 was also associated with extraversion. No such relationship was apparent for male respondents. These findings may suggest a gender difference in the use of smartphones for communication. Females tend, more than males, to prefer remote communication and to maintain close relationships by this means [16] [17]. Some females, therefore, regardless of situation, may prioritize replying promptly to a direct message. Such an obsession may, in turn, lead to depressive symptoms. Actually, for females, we found a correlation between subscale 2 and severe depression. Even so, it is hard to reliably establish any relationship between use of SNS and depressive symptoms [18] [19]. To better understand our present findings, we await the findings of future studies.

Meanwhile, only for males, subscales 1, 2, and 3 are negatively associated with agreeableness. This finding may suggest that some males use smartphones to escape 
from reality. In the present study, we found that males, compared to females, also spent more time playing online games $(Z=-2.48, p<0.05)$. A previous study also reported a negative correlation between problematic online game play and agreeableness [20]. Incidentally, subscale 2 is associated with emotional instability (i.e. neuroticism), which is consistent with a previous study that found a correlation between problematic online game play and neuroticism [20].

\section{Conclusion}

In this study, we found associations between smartphone dependence and general health status or personality traits, and also gender differences in these associations. Males seemed to immerse themselves in online games and females in online communications. In either case, extended use of smartphones correlated with poorer health. This research, however, has several limitations. First, all the subjects were medical students, which is too narrow to be representative of the same cohort in the general population. Second, owing to its cross-sectional design, this study is unable to clarify causal direction. These points require consideration in future studies. Even so, the present findings may be useful for providing smartphone guidance directed at university students. To further elucidate factors associated with smartphone dependence, we are planning further investigations.

\section{References}

[1] Ministry of Internal Affairs and Communications (2015) White Paper: Information and Communications in Japan, 2015.

[2] Brod, C. (1984) Technostress: The Human Cost of the Computer Revolution. AddisonWesley Publishing, Massachusetts.

[3] Toda, M., Nishio, N. and Takeshita, T. (2015) Development of a New Scale for Gauging Smartphone Dependence. Japanese Journal of Hygiene, 70, 259-263. http://dx.doi.org/10.1265/jjh.70.259

[4] Toda, M., Nishio, N. and Takeshita, T. (2015) Predictive Factors for Smartphone Dependence: Relationship to Demographic Characteristics, Chronotype, and Depressive State of University Students. Open Journal of Preventive Medicine, 5, 456-462. http://dx.doi.org/10.4236/ojpm.2015.512051

[5] Demirci, K., Akgönül, M. and Akpınar, A. (2015) Relationship of Smartphone Use Severity with Sleep Quality, Depression, and Anxiety in University Students. Journal of Behavioral Addictions, 4, 85-92. http://dx.doi.org/10.1556/2006.4.2015.010

[6] Ezoe, S., Toda, M., Yoshimura, K., Naritomi, A., Den, R. and Morimoto, K. (2009) Relationships of Personality and Lifestyle with Mobile Phone Dependence among Female Nursing Students. Social Behavior and Personality, 37, 231-238. http://dx.doi.org/10.2224/sbp.2009.37.2.231

[7] Igarashi, T., Motoyoshi, T., Takai, J. and Yoshida, T. (2008) No Mobile, No Life: Self-Perception and Text-Message Dependency among Japanese High School Students. Computers in Human Behavior, 24, 2311-2324. http://dx.doi.org/10.1016/j.chb.2007.12.001

[8] Goldberg, D.P. (1978) Manual of the General Health Questionnaire. NFER Publishing, Windsor.

[9] Gosling, S.D., Rentfrow, P.J. and Swann, W.B. (2003) A Very Brief Measure of the Big-Five 
Personality Domains. Journal of Research in Personality, 37, 504-528.

http://dx.doi.org/10.1016/S0092-6566(03)00046-1

[10] Berolo, S., Wells, R.P. and Amick 3rd, B.C. (2011) Musculoskeletal Symptoms among Mobile Hand-Held Device Users and Their Relationship to Device Use: A Preliminary Study in a Canadian University Population. Applied Ergonomics, 42, 371-378. http://dx.doi.org/10.1016/j.apergo.2010.08.010

[11] Shan, Z., Deng, G., Li, J., Li, Y., Zhang, Y. and Zhao, Q. (2013) Correlational Analysis of Neck/Shoulder Pain and Low Back Pain with the Use of Digital Products, Physical Activity and Psychological Status among Adolescents in Shanghai. PLOS ONE, 8, e78109. http://dx.doi.org/10.1371/journal.pone.0078109

[12] Gustafsson, E., Johnson, P.W. and Hagberg, M. (2010) Thumb Postures and Physical Loads during Mobile Phone Use: A Comparison of Young Adults with and without Musculoskeletal Symptoms. Journal of Electromyography and Kinesiology, 20, 127-135. http://dx.doi.org/10.1016/j.jelekin.2008.11.010

[13] Brunborg, G.S., Mentzoni, R.A., Molde, H., Myrseth, H., Skouverøe, K.J., Bjorvatn, B. and Pallesen, S. (2011) The Relationship between Media Use in the Bedroom, Sleep Habits and Symptoms of Insomnia. Journal of Sleep Research, 20, 569-575. http://dx.doi.org/10.1111/j.1365-2869.2011.00913.x

[14] Fossum, I.N., Nordnes, L.T., Storemark, S.S., Bjorvatn, B. and Pallesen, S. (2014) The Association between Use of Electronic Media in Bed before Going to Sleep and Insomnia Symptoms, Daytime Sleepiness, Morningness, and Chronotype. Behavioral Sleep Medicine, 12, 343-357. http://dx.doi.org/10.1080/15402002.2013.819468

[15] Suganuma, N., Kikuchi, T., Yanagi, K., Yamamura, S., Morishima, H., Adachi, H., Kumano-Go, T., Mikami, A., Sugita, Y. and Takeda, M. (2007) Using Electronic Media before Sleep Can Curtail Sleep Time and Result in Self-Perceived Insufficient Sleep. Sleep and Biological Rhythms, 5, 204-214. http://dx.doi.org/10.1111/j.1479-8425.2007.00276.x

[16] Boneva, B., Kraut, R. and Frohlich, D. (2001) Using Email for Personal Relationships: The Difference Gender Makes. American Behavioral Scientist, 45, 530-549. http://dx.doi.org/10.1177/00027640121957204

[17] Toda, M., Monden, K., Kubo, K. and Morimoto, K. (2006) Mobile Phone Dependence and Health-Related Lifestyle of University Students. Social Behavior and Personality, 34, 1277 1284. http://dx.doi.org/10.2224/sbp.2006.34.10.1277

[18] Jelenchick, L.A., Eickhoff, J.C. and Moreno, M.A. (2013) “Facebook Depression?" Social Networking Site Use and Depression in Older Adolescents. The Journal of Adolescent Health, 52, 128-130. http://dx.doi.org/10.1016/j.jadohealth.2012.05.008

[19] Pantic, I., Damjanovic, A., Todorovic, J., Topalovic, D., Bojovic-Jovic, D., Ristic, S. and Pantic, S. (2012) Association between Online Social Networking and Depression in High School Students: Behavioral Physiology Viewpoint. Psychiatria Danubina, 24, 90-93.

[20] Peters, C.S. and Malesky, L.A. (2008) Problematic Usage among Highly-Engaged Players of Massively Multiplayer Online Role Playing Games. Cyberpsychology \& Behavior, 11, 481484. http://dx.doi.org/10.1089/cpb.2007.0140 
Submit or recommend next manuscript to SCIRP and we will provide best service for you:

Accepting pre-submission inquiries through Email, Facebook, LinkedIn, Twitter, etc. A wide selection of journals (inclusive of 9 subjects, more than 200 journals)

Providing 24-hour high-quality service

User-friendly online submission system

Fair and swift peer-review system

Efficient typesetting and proofreading procedure

Display of the result of downloads and visits, as well as the number of cited articles

Maximum dissemination of your research work

Submit your manuscript at: http://papersubmission.scirp.org/

Or contact ojpm@scirp.org 